Available online at JSJ: Jurnal Studi Jurnalistik

http://journal.uinjkt.ac.id/index.php/jsj

JSJ: Jurnal Studi Jurnalistik, 1 (1), 2019, 1-13

\title{
Makna Agama dan Budaya di dalam Foto Karya Rony Zakaria Berjudul Men, Mountains and the Sea
}

\author{
Hana Sayyida \\ hanasayyida@yahoo.com \\ Kholis Ridho \\ kholis.ridho@uinjkt.ac.id \\ Fidikom UIN Syarif Hidayatullah Jakarta
}

\begin{abstract}
ABSTRAK
Foto documenter bertema hubungan manusia, gunung dan laut karya Rony Zakaria berjudul Men, Mountains and the Sea menurut penulis penting dikaji. Karena di dalamnya merepresentasikan tata cara hidup yang diyakini, dijalani, dan dikembangkan sebagai pandangan hidup umumnya masyarakat Jawa. Akulturasi agama dan budaya, yang diantaranya dicerminkan dari upacara keagamaannya, merupakan bukti bahwa agama tidak hadir dalam ruang yang hampa budaya. Foto dokumentasi tersebuttidak saja bernilaihistoris, tetapi juga ke depan dapat menjadi pijakan habituasi cultural bagi masa depan generasi suku Jawa.

Penelitian ini menggunakan paradigma konstruktivis dengan pendekatan kualitatif melalui model analisis semiotika Roland Barthes. Yakni memberi titik tekan pada makna denotasi, konotasi, dan mitos yang ditafsirkan melalui prespektif makna budaya yang dikembangkan dalam keilmuan antropologi, sosiologi dan sejarah.

Hasil analisa buku foto ini didapatkan kesimpulan bahwa manusia Jawa tidak dapat meninggalkan kelestarian alam semesta sebagai bagian dari kehadiran Tuhan di dunia. Alam semesta itu dapat berupa gunung dan laut, yang juga adalah penghidupan yang melekat dalam keseharian mereka. Meskipun pergeseran zaman telah memasuki sistem keyakinan keagamaan mereka, namun agama local tetap bertahan dan terus hidup di masyarakatnya.
\end{abstract}

Kata Kunci: Semiotika, Foto Dokumenter, Representasi, Suku Jawa

Permalink/DOI: http://doi.org/10.15408/jsj.v1.13928

\section{A. PENDAHULUAN}

Koentjaraningrat(1974)membagiunsur-unsur kebudayaan terdiri dari sistem religi dan upacara keagamaan, sistem dan organisasi kemasyarakatan, sistem pengetahuan, bahasa, kesenian, sistem pencarian sistem teknologi peralatan. ${ }^{1}$ Dalam

\footnotetext{
${ }^{1}$ Rusmin Tumanggor, dkk, IImu Sosial dan Budaya
}

sistemreligi,terdapatkomponen-komponen,yaitu adanyaumatberagama, sistemkeyakinan, sistem peribadatan/ritual, sistem peralatan ritual,dan emosi keagamaan.

Dalam masyarakat Jawa, terdapat upacara keagamaan sekaligus budaya yang dilaksanakan

Dasar, (Jakarta: Kencana, 2010), hal. 22 
secara masif, sebut diantaranya upacara Labuhan ${ }^{2}$ di Yogyakarta, dan upacara Kasada di Bromo. Pada upacara Labuhan terdapat suatu kepercayaan yang unik. Masyarakat melakukan upacara penghormatan serta persembahan sesaji kepada ruh halus yang berkuasa di suatu tempat dengan tujuan meminta keselamatan Sri Sultan sebagai penguasa keraton dan juga untuk keberlangsungan hidup rakyat Yogyakarta. Labuhan juga sebagai bentuk rasa syukur masyarakat Yogyakarta kepada penguasa Pantai Selatan, NyiRoroKidulatasperlindungan yang diberikan. Upacara Labuhan diselenggarakan di beberapa tempat, yaitu Pantai Parangkusumo, Gunung Merapi, dan Gunung Lawu.

Serupa dengan upacara Labuhan, masyarakat Tengger juga melakukan upacara keagamaan yang dikenal dengan nama upacara adat Kasada, yang digelar setahun sekali pada tanggal 14-16 bulan Kasadabertepatanbulanpurnamatampakdilangit secarautuh. ${ }^{3}$ Upacara Kasada merupakanbentuk ucapan terima kasih kepada Sang Hyang Widhi karena telah memberikan kenikmatan, keselamatan, kemakmuran, dan limpahan hasil bumi.Selainitu, upacara dilakukan sebagai bentuk penghormatan terhadap leluhur.Dalam pelaksanaannya, masyarakat Tengger berkumpul lalu mendaki bibir kawah Gunung Bromo dengan membawa hasil bumi serta ternak peliharaan sebagai sesaji yang ditata di tempat bernama Ongkek. Setelah itu,seluruhsesajidilemparkan kekawahgunung.

Keduaupacarakegamaandanbudayatersebut adalah contoh dari sebagian upacara yang tumbuh dan berkembang pada masyarakat lokal di Indonesia. Banyak fotografer yang mendokumentasikan kebudayaan atau upacara keagamaan, misalnya ArbainRambey,FerryLatief,ataupunDonHasman. Namun hanya sedikit yang mendokumentasikan

${ }^{2}$ Labuhan berasal dari kata 'Labuh' berarti membuang sesuatu ke air baik sungai ataupun laut. Aristo Farela, $A$ Short History of Java, (Surabaya: Ecosystem Publishing, 2017), hal. 127

${ }^{3}$ Aristo Farela, A Short History of Java Sejarah Singkat Tentang Pulau Jawa, Kultur, Manusia, dan Budayanya, (Surabaya: Ecosystem Publishing, 2017), hal. 123 upacara keagamaan masyarakat lokal di Indonesia secara cukup detail. Dan Rony Zakaria, ${ }^{4}$ hemat penulis, adalahsalahsatudarifotografertersebut. yang berhasil membuat karya foto dokumenter tentang hubungan antara manusia dengan alam yaitu gunung dan laut. Dengan bekal pendidikan fotografi jurnalistik di Galeri Foto Jurnalistik Antara, lalu melanjutkan pendidikan fotografi di Asian Center for Journalism di Manila Filipina. Ia berhasil membuat foto-fotonya menjadi sebuah rangkaian cerita dan didokumentasikan selama kurun waktu delapan tahun. Ia menemukan betapa gunung dan laut memiliki tempat khusus dalam spiritualitas masyarakat Jawa. Hal itulah yang dirasakan oleh Rony Zakaria, hingga ia memutuskan untuk membuat foto dokumenter hitam putih yangtidak sekadar bercerita tentang panoramaalamIndonesiayangindah,tetapidibalik keindahahan ternyata masih berhubungan dengan kekayaan ritual keagamaan dan budayatradisional.

Bagi Rony, keberagaman masyarakat Tengger dan Yogyakarta tergolong unik. Karena, meskipun secara formal mereka beragama Hindu, Islam,

\footnotetext{
${ }^{4}$ Kisah foto Men, Mountains and the Sea yang dibuat oleh Rony Zakaria telah dipublikasikan di majalah Destin Asian Indonesia. Karya-karyanya lainya juga diakui dunia dan telah dimuat di beberapa media asing sepertiThe New York Times, Lens Culture, Invisible Photographer Asia, Deutsche Welle, Prospekt Photo (Italy), The Manuel Rivera-Ortiz Foundation (London, New York, Paris, Zurich), dan lainnya. Rony telah bekerja dan mempublikasikan karyanya di berbagai media nasional dan luar negeri antara lain TIME asia, The New York Times, National Geographic, Le Monde, Guardian, Mare, Vice, Geo, Monocle, The Wall Street Journal, Marie Claire, The Financial Times, Bloomberg News, Courier Iternational, DeVolkskrant, DestinAsian, Tempo, dan Jakarta Post. Tak hanya itu, ia juga kerap kali memotret untuk berbagai perusahaan, seperti Microsoft, Asian Development Bank, The World Bank, GIZ, The Netherlands Embassy, AusAid, AirBnB, British Embassy, Holcim, CBI Europe, Novartis, Porsche Indonesia, Global Aid Network, Sinarmas Maverick, dan juga Chuosenko. Karyanya pun telah dipamerkan di berbagai galeri dan festival di Indonesia, Italia, Perancis, Jerman, Singapura, Thailand, Filipina, Bangladesh, China, dan Malaysia. la menerbitkan buku pertamanya, Encounters pada tahun 2013.
} 
Katolik, Protestan, Budha ataupun Konghuchu tetapi dalam praktiknya mereka juga menerapkan tradisi-tradisi lokal. Akulturasi Islam dengan agama lokal tercermin dalam sistem religi masyarakat yang dipraktikkan. Rony Zakaria berupaya mendokumentasikankedalamfotoakulturasiyang diberi judul Men, Mountains and the Seatersebut sebagai warisan yang penting untuk diketahui generasi bangsa.

Lalu apakah yang sebenarnya ingin disampaikan olehRonyZakariadalamfotoMen,Mountainsand the Sea ini. Dengan dasar itulahpenulis mencoba menganalisis maksud yang terkandung dalam foto dengan cara analisis semiotika. ${ }^{5}$ Analisis semiotika dirasa tepat untuk menjabarkan atau mencari arti yang terkandung dalam foto-foto manusia, gunung, dan laut karya Rony Zakaria. Diperkuat olehpendapat Paul Messarisyangterdapatdalam bukuKisahMatakaryaSenoGumiraAdjidarma, ${ }^{6}$ ia mendukung asumsi bahwa di alam suatu foto sebagai media visual, bukan hanya dimungkinkan untuk menarik suatu makna, melainkan bahwa makna itu mungkin direkayasa untuk tampil dengan gagasan menghujam. Sebuah foto jadinya bukan hanya representasi visual objek yang direproduksi, melainkan mengandung pesan.

\section{B. METODOLOGI PENELITIAN}

Paradigmayangdigunakan dalam penelitian ini adalah konstruktivisme dengan pendekatan kualitatif. Riset kualitatif bertujuan untuk menjelaskan fenomena dengan sedalamdalamnya melalui pengumpulan data sedalamdalamnya. ${ }^{7}$ Melalui pendekatan kualitatif ini

\footnotetext{
5 Semiotik merupakan ilmu tentang tanda. Menurut Preminger (2011), ilmu ini menganggap bahwa fenomena sosial atau masyarakat dan kebudayaan itu merupakan tanda-tanda. Rachmat Kriyantono, Teknik Praktis Riset Komunikasi Disertai Contoh Praktis Riset Media, Public Relations, Advertising, Komunikasi Organisasi, Komunikasi Pemasaran, (Jakarta: Kencana, 2006), h.265

${ }^{6}$ Seno Gumira Ajidarma, Kisah Mata, Fotografi antara Dua subjek: Perbincangan tentang Ada, (Yogyakarta, Galang Press, 2002), h.27

${ }^{7}$ Rachmat Kriyantono, Teknik Praktis Riset Komunikasi
}

penulis berupaya menjelaskan fenomena upacara Labuhan di Yogyakarta dan upacara Kasada di Tengger Probolinggo. Untukmetodeanalisisnya menggunakan semiotika, yaitu ilmu yang mengkaji tanda dalam kehidupan manusia, dimana di balik fakta akan selalu ada makna. ${ }^{8}$ Dan semiotika yang dipilih adalah teori yang dikemukakan oleh RolandBarthesyangterdiridaritigatahapandalam membaca sebuah makna, yaitu denotasi, konotasi, dan mitos.

Data primer dalam penelitian ini enam dari sembilan foto yang terdapat dalam majalah DestinAsian Indonesia yang menggambarkan hubungan masyarakat Yogyakarta dengan alam yaitu Pantai Parangkusumo dan Gunung Merapi dalam upacara Labuhan, serta kehidupan masyarakat Tenggerdanwujudpenghormatanmerekaterhadap kekuatan supranatural dalam upacara Kasada. Sedangkan data sekunder diperoleh dari wawancara denganfotograferRonyZakaria,buku-buku,artikel danserta menambahkanbeberapa referensi yang berkaitan dengan penelitian ini.

\section{HASIL PENELITIAN}

Setelah memberikan penjelasan arah kajian semiotika pada buku foto karya Rony Zakaria. Berikut penulis paparkan makna foto berdasarkan urutan foto, yaitu (1) tentang foto panorama Gunung Batok dan Gunung Bromo menjelang digelarnya upacara Kasada,(2) foto terkait suasana upacara Labuhan, (3) foto tentang pria Tengger yang mengendarai kuda, (4) foto tentang peserta upacara Kasada sedang berdoa di atap Gunung Bromo,(5) fototentangseorangpriayangberada di puncak Merapi, dan (6) foto terakhir bercerita tentang wisatawan yang sedang mandi di Pantai Parangtritis.

\footnotetext{
Disertai Contoh Praktis Riset Media, Public Relations, Advertising, Komunikasi Organisasi, Komunikasi Pemasaran, (Jakarta: Kencana, 2006), h. 56

${ }^{8}$ Benny H. Hoed, Semiotik dan Dinamika Sosial Budaya, (Depok: Komunitas Bambu, 2014), h. 5
} 


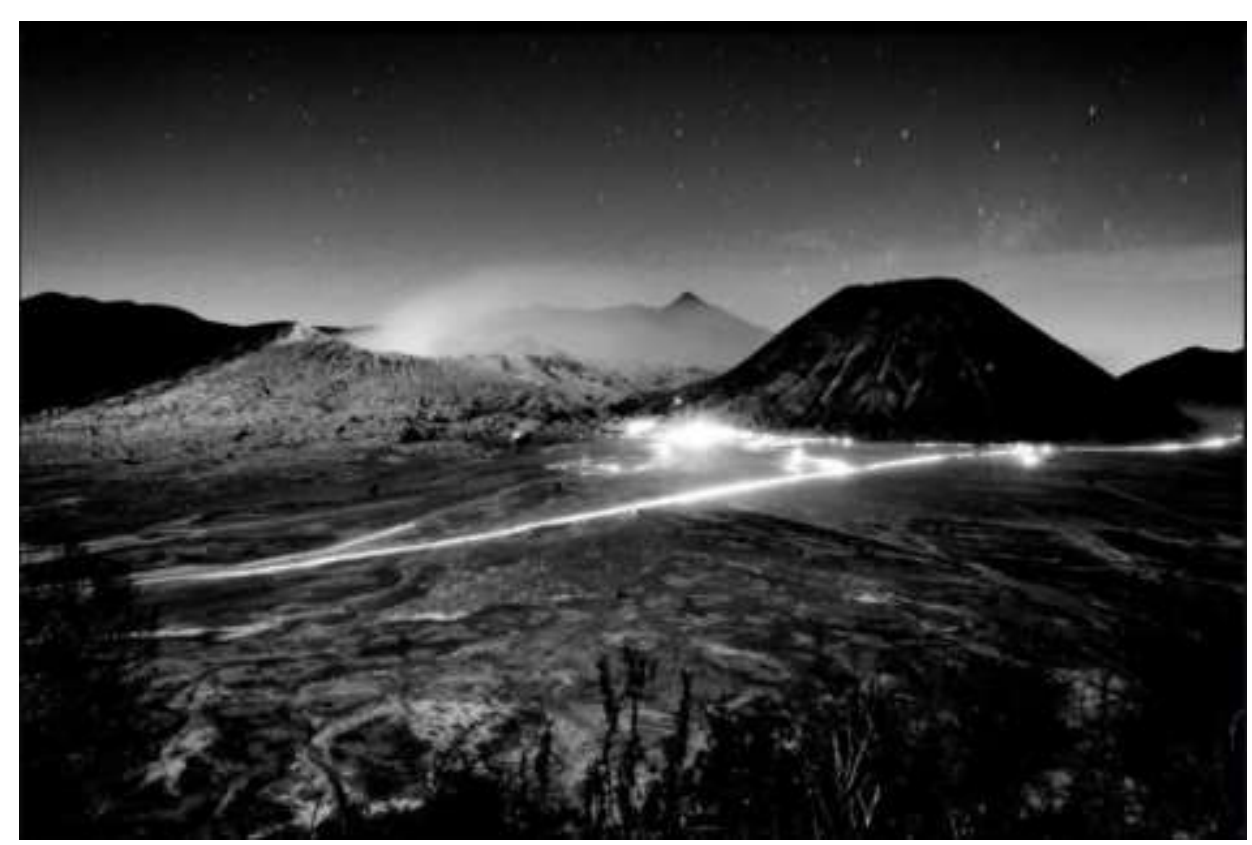

Gambar 1. Foto Pertama Sumber: File Data Men, Mountains and the Sea Karya Rony Zakaria

tinggi hingga ke langit. Asap tersebut merujuk pada asap darikemenyan yang dibakar ketika pelaksanaan upacara Kasada. Asap kemenyan dimaknai doa- doa manusia ke langit hingga dikabulkan oleh Tuhan, sekaligus wujud penghormatan mereka terhadap Sang Hyang Widhi. Selain itu, mitos pada foto ini adalah tumbuhnya kehidupan baru pada masyarakat Tengger yang tergambar adanya garis cahaya di

\section{Foto Pertama}

Fotopertamatidakmengandungtrickeffectatau mengubah keaslian foto saat dipotret di kamera. Tapi, foto ini juga tidak sama persis seperti yang ada pada realita yang terlihat saat berada langsung dilokasipemotretan,karenadilakukanpengubahan warna menjadi hitam putih melalui komputer. Hal tersebut menimbulkan pesan konotatif yang membuat pemandangan pada foto menjadi sesuatu yang gelap, hingga memberikan kesan yang dekat dengan mistis, atau keheningan. Seperti yang dibahas di dalam situs internet goodminds. id mengenai arti warna dalam psikologi warna menurutparaahli ${ }^{9}$, warnahitamadalahwarnayang akanmemberikesansuram,gelapdanmenakutkan namun juga elegan. Hitam juga melambangkan keanggunan (elegance), kemakmuran (wealth) dan kecanggihan (sopiscated), juga merupakan warna yang independent dan penuh misteri. Sedangkan warna putih sebagai warna yang murni dan tidak menggunakancampuranapapunmemberiartiyang suci dan bersih.

Mitos yang tergambar pada foto ini terlihat dari asap dari kawah Bromo yang membumbung

\footnotetext{
${ }^{9}$ https://goodminds.id/arti-warna/ (Diakses pada Juni 2018)
}

bagian kaki gunung. Berdasarkan keterangan yang diberikanolehRonyZakaria ${ }^{10}$,gariscahayatersebut berasal dari kendaraan yang lalu-lalang. Adanya kemajuan teknologi, membuktikan bahwa adanya kehidupan yang baru pada masyarakat Tengger.

\section{Foto Kedua}

Foto kedua tentang suasana pelaksanaan upacara Labuhan di Pantai Parangkusumo, Yogyakarta. Nampak beberapa orang menggulung celana hingga ke atas lutut dan kaki yang sudah tertutup air. Di sebelah kanan foto terdapat pria mengenakan batik dan sarung di tubuh, serta peci di kepalanya. Sebelah kiri, terdapat pria mengenakan caping. Sedangkan pria yang berdiri di paling depan terlihat sedang melipat kedua tangannya dan wajahnya hanya terlihat bagian mulut dan dagu. Foto tersebut ditempatkan setelah foto pertama (panorama pegunungan), menggambarkan kelanjutan cerita, dalam foto ini tergambar hubungan masyarakat Yogyakarta terhadapalam, yaitu lautyangdiwujudkandengan kegiatan upacara Labuhan.

\footnotetext{
${ }^{10}$ Wawancara Pribadi dengan Rony Zakaria pada 22 Juni 2018
} 


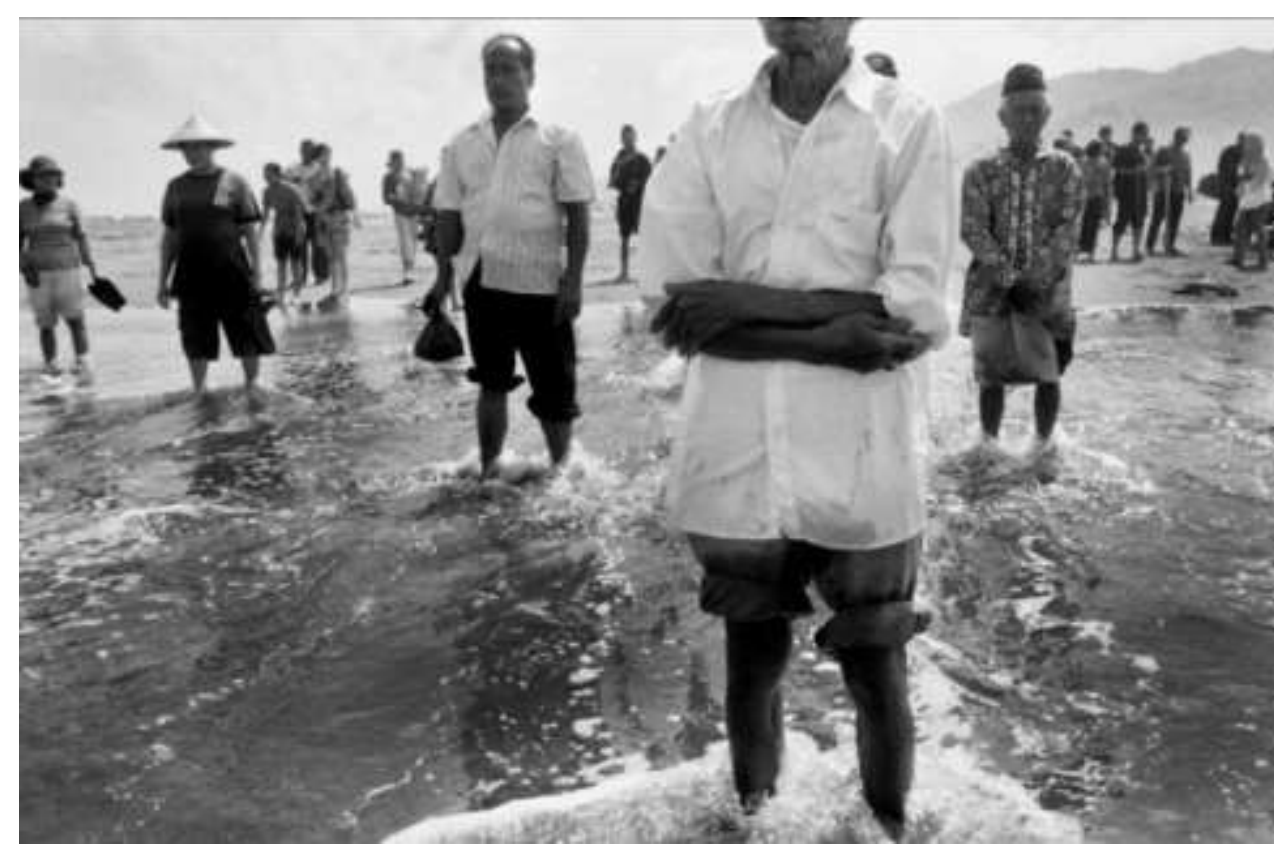

Gambar 2. Foto Kedua

Sumber: File Data Men, Mountains and the Sea Karya Rony Zakaria

Terlihat orangorang berada di pinggir laut,dimanamasyarakat Yogyakarta melakukan upacara Labuhan sebagai ucapan syukur danterimakasihkepada sang penjaga karena sudah melindungi mereka dari bencana, dan membantu menjaga ketentraman di Keraton danjugabagikehidupan masyarakat.

\section{Foto Ketiga}

Foto ketiga tentang

Teknis pengambilan foto menggunakan lensa rata-rata $35 \mathrm{~mm}$, dan terlihat kedekatan antara fotografer dan subjek yang difoto. Terhadap fotonya,sangfotograferjarangbahkanhampirtidak pernah melakukan cropping/pemotongan gambar melaluikomputer. Pemotonganwajahdilakukan saat fotografer memotret, dari viewfinder kamera. Penulis melihat, pemotongan tersebut bertujuan agar fokus langsung tertuju ke tangan pria yang berdiri paling depan.

Mitos dalam foto ini muncul dari pose atau gerak tubuh pria yang melipat kedua tangannya, seperti bersedekap dengan khusyuk ketika sholat, namun yang tergambar dalam foto adalah masyarakat sedang khusyuk dalam melaksanakan upacara Labuhan. Sehingga mitos dalam foto ini adalah mengenai kekhusyukan ketika menjalankan ritualdalamibadahataupunupacara keagamaan.

Selainitu, dalamfototergambarberagamnya pemeluk agama, terlihat dari pakaian yang dikenakan.Sarung dan peci melambangkan Islam, sedangkan caping melambangkan kepercayaan masyarakat nelayan, bahwa laut memiliki kekuatan magis sehingga perlu perlakuan khusus dalam melakukan penangkapan ikan agar keselamatan dan hasil tangkapannya semakinterjamin.
Pria Tengger sedang mengendarai Kuda di kawah Gunung Bromo. Suasana tampak sepi karena tidak nampak orang lain di sana. Kuda bersama orang yang mengendarai terlihat begitu kecil di komplekskalderapurba. Padafotoini, fotografer menempatkan figure atau point of interests tepat pada bagiantengahfoto. Jadi, mataakanlangsungtertuju pada figure tersebut. Dalam persepsi visualgestalt dikatakan sebagai figure and ground yang berarti fotografer memandang setiap bidang pengamatan dapatdibagimenjadidua, yaitufigure(bentuk) dan ground(latarbelakang). ${ }^{11}$ Jadidengansengajaatau tidak, secara sendirinya ketika memotret, fotografer akanmenentukanmanabagianyangakanmenjadi latarbelakang, dan manayangakanmenjadipoin utamaataufigurepadafotoyang ia buat. Padafoto ini, yang menjadi figure adalah orang tengger yang sedang menunggangi kuda.

Objek manusia yang kecil di antara kaldera purbayangbegitubesar, menggambarkanbahwa manusia hanyalah makhluk kecil, dibandingkan dengan alam yang begitu besar, terlebih di mata Tuhan. Mitos lainnya adalah para lelaki Suku Tengger mengendarai kuda sebagai kendaraan

11 https://snapshot.canon-asia.com/indonesia/article/id/ gestalt-theory-in-street-photography (Diakses pada Juni 2018) 
mereka, sehingga Kuda jugamenjadilambang kejantanan.Kuda yang ditunggangiolehorang Tengger yg terlihat pada foto juga menjadi gambaran kehidupan masyarakat Tengger yang sangat sederhana. Terlihat dari carahidup yang masih tradisional. Raffles dalam bukunya "The History of Java”, ia seolah mengagumi orang-orang Tengger yang hidup dalam keteraturan dan damai. Merekajuga digambarkan

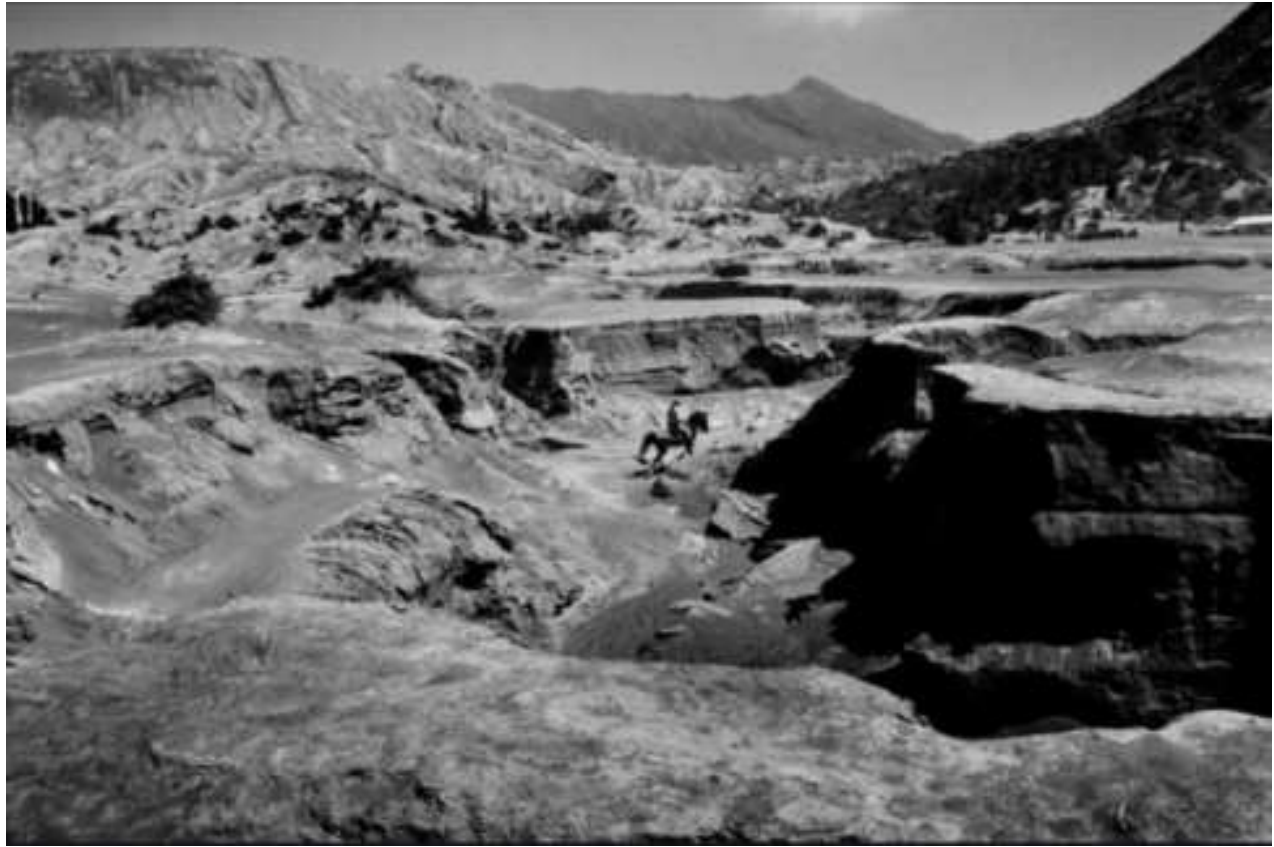

Gambar 3. Foto Ketiga

Sumber: File Data Men, Mountains and the Sea Karya Rony Zakaria sebagai para pekerja yang jujur dan jauh dari halhal aneh yang merusak moral seperti di perkotaan. Laporan-laporan peneliti Belanda lainnya menyatakan bahwa orang Tengger mengenal dewadewa Hindu yang menjadi bagian dari kegiatan peribadatan mereka. ${ }^{12}$

\section{Foto Keempat}

Fotokeempattentangsalahseorangpartisipan upacara Kasada yang sedang berdoa di atas Gunung Bromo, Yogyakarta. Difotoini, seorang pria memakai topi bertuliskan "world cup" dan mengenakan kain bermotif menutupi tubuhnya. Ia berdirididekatsepertipagar, denganmerekatkan kedua telapak tangannya serta ujung jarinya menempeldidekatdagudanmulut. Sedikitterlihat juga pegunungan sebagai latar belakangnya.

Pose priayang merupakan masyarakat Tengger tersebut dipotret secara natural tanpa mengatur gerak tubuh objek yang diphoto. Fotografer hanya menangkap apa yang ia lihat di depannya, sesuai dengankenyataanyangterjadi.Makadariitu,dapat dimaknai bahwa pria tersebut sedang berdoa dengan

\footnotetext{
12 http://www.wacana.co/2015/10/tengger-sejarah-legenda-danbudayanya/ (Diakses pada Juni 2018)
}

posisimatamelihatkebawahyangartinyaiatunduk di hadapan Hyang WidhiWasa.

Hampir di setiap foto, digunakan lensa dengandiameter $35 \mathrm{~mm}$. Nampakfotoinidiambil dengan sudut pandang high angle, dengan posisi

Gambar 4. Foto Keempat

Sumber: File Data Men, Mountains and the Sea Karya Rony Zakaria

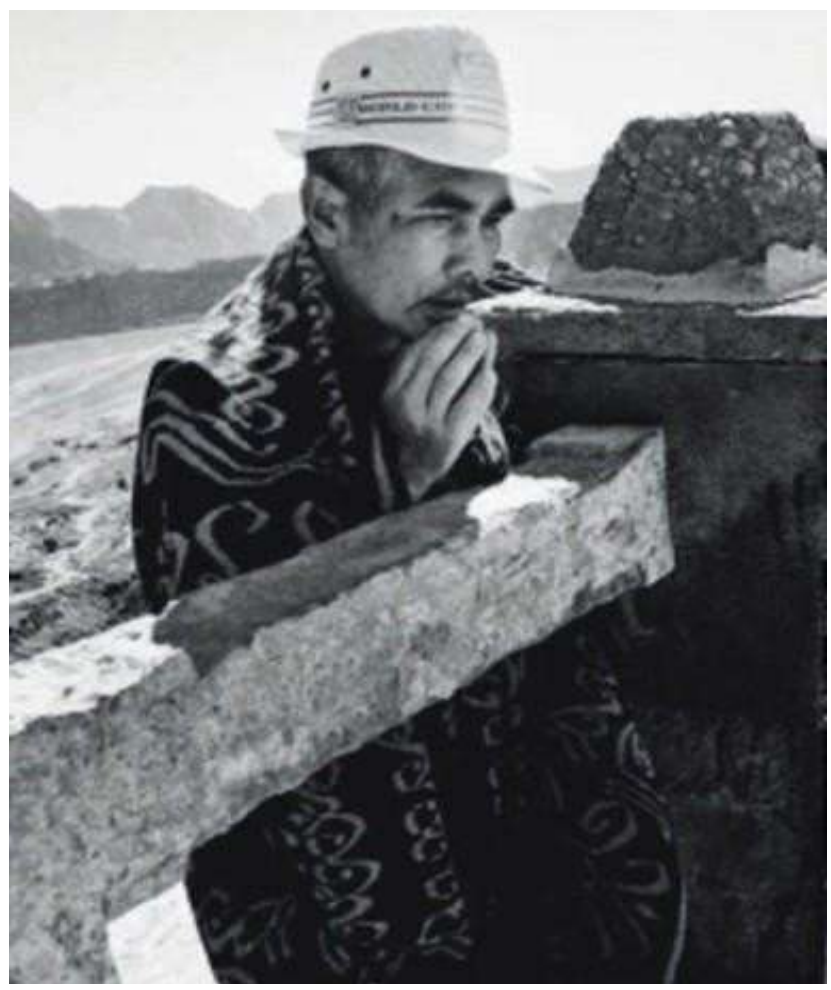


kamera sedikit lebih tinggi dari objek sehingga menimbulkan kesan bahwapriaTenggerpadafototerlihat berada di posisi lebih rendah dan ia hormatpadasesuatuyanglebihtinggi darinya. Foto diambil menggunakan lensa dengan bukaan diafragma kecil danmenghasilkanruangtajamyang sempit.

Jika pada foto sebelumnya bercerita tentang kesederhanaan dan cara hidup masyarakat Tengger yang masih tradisional. Dalam foto ini digambarkan, meskipun sederhana dan masih menggunakan tata cara tradisional, masyarakat Tengger tidak menutup diri dari modernitas. Foto ini menjelaskan detil manusia, dalam hal ini adalah masyarakat Tengger.

Mitos yang muncul dalam foto ini adalah manusia melakukan hubungan dengan Tuhan, berkomunikasi melalui doa. Di mana ketika doa, manusia menyampaikan harapan dan keinginannya. Doa juga merupakan salah satu ritual yang ada dalam upacara Kasada, yakni masyarakat Tengger mengharapkan rezeki yang melimpah serta terlindung dari bahaya.

Foto ini juga mengandung mitos akulturasi agama dan budaya lokal serta modernitas. Berhubungan dengan foto sebelumnya, yang mengandung pesan tentang kehidupan tradisional masyarakat Tengger. Sebaliknya, foto ini menggambarkan bahwa masyarakat Tengger tidak menutup diri dari modernitas.Jika disimpulkan, terdapat benang merahdi mana ada proses akulturasi di sini. Sebagian masyarakat Tengger mempertahankan kehidupan tradisionalnya, tetapi adajuga sebagian besaryang beradaptasi dengan agamabarudanjugamodernitas. Modernitasyang dimaksud adalah adanya teknologi, kebudayaan lokalbercampurkebudayaanbaru,topifedorayang dikenakanolehpriaTengger,sertakebaharuanjuga

\section{Foto Kelima}

Fotokelimatentangseorangpriayangberada di puncak Gunung Merapi dengan latar belakang Gunung Sindoro dan Gunung Sumbing. Pada foto kelima, terlihat pose pria sedang berjalan menundukkan kepala. Kedua tangannya terlihat menarik sarung yang ia kenakan, menimbulkan makna bahwa ia sedang kedinginan. Badan yang terlihat sedang menanjak, menimbulkan makna akan ke tempat yang lebih tinggi.

Padafotokelimaini, tidakterlihatobjekyang beragam.Namunsepertiyangsudahdikemukakan sebelumnya mengenai figure and ground, terlihat fotografer menempatkan pria yang sedang berjalan di ketinggian, yang merupakan kawasan puncak Gunung Merapisebagaifigure, dan duagunungdi belakangnya yaitu Gunung Sindoro dan Gunung Sumbing menjadi latar belakang foto. Awan kabut yangmunculmenambahkankesanmistispadafoto. Pria tersebut terlihat mengenakan kain sarung, digunakan untuk menghangatkan tubuh. Latar belakang langit menggambarkan kondisi cuaca 
yang cerah., namun awan kabut yang muncul memberikan kesan dekat dengan suasanamistis.

Figure diletakkan bagian tengah bawah, sedangkan $2 / 3$ gambar bagian atas berisi hiasan Gunung Sumbing serta Gunung Sindoroyangtertutupawan, hanya muncul di bagian puncaknya. Bagian kosong di belakang figure memberikan kesan bahwa figure bergerak meninggalkan bagian kosong tersebut. Foto ini membentuk suatu rangkaian yang saling bersambung dengan foto lain, penanda konotasi tidak dapatlagipadamasing-masingfoto,

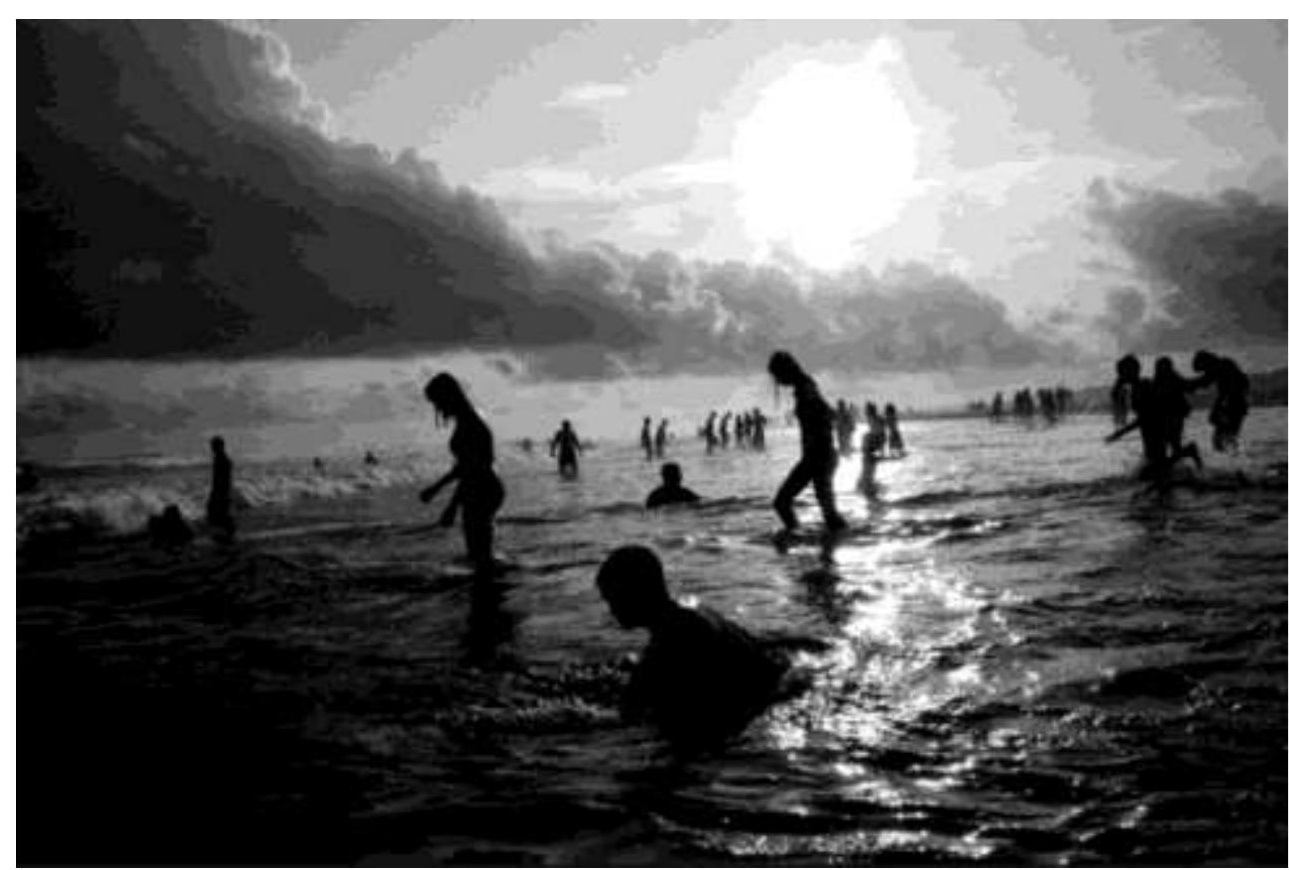

Gambar 6. Foto Keenam

Sumber: File Data Men, Mountains and the Sea Karya Rony Zakaria tetapi pada keseluruhan rangkaian yang membentuk satu-kesatuan. Foto ini seperti bersambungdarifotosebelumnya, menceritakan bahwamanusiahidupberdampingandenganalam.

Puncak gunung melambangkan ketinggian, yang letaknya berada di atas. Menggambarkan kepercayaan bahwa Tuhan ada di atas, Yang Maha Tinggi. Pria yang berada di puncak Gunung Merapi menggambarkan kepercayaan masyarakat Gunung tentang sistem pengetahuan yang mereka gunakan untuk beradaptasi dari karakter gunung dimana mereka tinggal. ${ }^{13}$ Kehidupanmasyarakat gunung tidaklepasdaricuaca,dimanacaramereka bertahan hidup dengan menyesuaikan iklim, dan selalu mendekatkan diri dengan alam.

Foto ini juga menggambarkan interaksi antara manusiadengangunung. Sebelum Hindu/Budha masuk ke Nusantara, masyarakat mempersepsi puncak gunung adalah tempat bersemayamnya roh-roh. ${ }^{14}$ Gunung seringkali dianggap sakral bagi masyarakat.Begitu pula dengan masyarakat

\footnotetext{
${ }^{13}$ Lucas Sasongko Triyoga, Merapi dan Orang Jawa (Jakarta: Grasindo, 2010), h.166

14 https://indonesiana.tempo.co/read/71612/2016/04/23/ hando-kowidagdo/merapi-dan-orang-jawa (Diakses pada Juni 2018)
}

Yogyakarta yang menganggap Puncak Merapi adalah tempat yang sakral hingga upacara Labuhan juga dilaksanakan di sana.

Menurut sejarawan, filsuf, penulis fiksi Rumania dan Profesor Universitas Chicago, Mircea Eliade, gunungyangsakralmenjadisimbolbanyakhal.Ada yangmenganggapbahwagunungsebagaitempat suci, gunung dianggap sebagai Tuhan, gunung yangsanggupmemberikankekuatansuper,danada yang beranggapan bahwa gunung adalah tempat hidup dan mati suatu bangsa. ${ }^{15}$

\section{Foto Keenam}

Fotokeenamtentangwisatawanyangsedang mandi di Pantai Parangtritis, Yogyakarta. Pose dalam foto ini mungkin dapat penulis katakan sebagai gerak tubuh, karena biasanya pose identik dengan gaya tubuh yang diatur. Pada foto ini, terlihat gerak tubuh yang berbeda. Satu gestur, terlihat duduk di antara air sementara lainnya terlihat berdiri dengan lekukan tubuh, layaknya siluet pada foto. Dari bentuk siluet yang terlihat,

\footnotetext{
${ }^{15}$ https://phinemo.com/makna-kesakralan-gunung-dariberbagai-negara/
} 
orang-orang berjalan ke arah kiri, yang dalam fotografi bermakna kembali dari suatu tempat.

Objek pada foto ini, yaitu orang-orang yang merupakan wisatawan yang sedang mandi di pantai, namun terlihat mistis karena dipotret ke dalam bentuk siluet. Selain itu juga terlihat awan yang bergumpal yang memberikan kesan dramatis, dan matahari bersinar hingga cahayanya memantuldipermukaanair. Mataharimemberikan konotasi bahwa adanya kehidupan dan harapan. Dengangambarantersebutdapatdiketahuiteknis pengambilan foto menggunakan lensa dengan diameter lebar, agar bisa menangkap banyak informasi dan menjadikannya ke dalam visual. Fotodiambil berlawanandengan arah datangnya cahayamatahari sehinggaorang-orangpada foto menjadi siluet. Hasil dari foto siluet tersebut memberikan kesan yang mistis. Yakni dipahami dari gambaran orang-orang yang berenang di alut, tetapi direpresentasikan seolah-olah dalam wujud yang lain karena tidak tergambar wujud manusia secara utuh yang berkeliaran di pantai.

Dari foto orang-orang yang sedang berenang, munculmitosbahwamandidilautadalahpenyucian jiwa, atau sering terdengar istilah "buang sial". Sedangkandarisiluetyangtergambardalamfoto, muncul makna seolah-olahmanusia adalah sama di mata Tuhan. Terlihat dari semua wujud yang sama, hanya terlihat dalam bentuk siluet, hitam seakan-akan kotor sehingga orang-orang mandi di lautuntukmembersihkandiri. Orang-orangyang berjalan ke arah kiri, dalam fotografi artinya kembali ke suatu tempat, yaitu kembali ke kesucian diri.

Dalam foto terdapat laut, yang menjadi gambaran perwujudan Tuhan bagi masyarakat Jawa sejak zaman purbayang menganut animisme dandinamisme, yaitu tundukpadagejalaalamiah dan benda-benda alam, sehingga ketundukkan tersebut lahir ke dalam bentuk menyembah dan mempertuhankan benda alam seperti matahari, bulan, bintang, gunung, lautan, danlain-lain. ${ }^{16}$

\footnotetext{
${ }^{16}$ Aristo Farela, A Short History of Java (Surabaya:
}

\section{PEMBAHASAN}

Dimana relasi manusia, gunung, dan lautan dapat, direpresentasikan? Sekuranganya terbagi menjadi dua premis, yaitu makna gunung dan laut bagimasyarakat Jawa,danmaknaupayamanusia Jawa saat bertahan dengan sistem keyakinannya melalui akulturasi budaya dan agama. Sehingga agama lokal terus beradaptasi dengan sistem nilai baru, termasuk modernitas. Sebagaimana digambarkan dalam buku "Merapi dan Orang Jawa"yangditulisoleh Lucas Sasongko Triyoga, kemudian dikutip oleh indonesiana.tempo. co, ${ }^{17}$ dijelaskan bahwadi Indonesia, interaksi manusia tersebut tergambar dari pandangan masyarakat terhadap gunung. Dimana sebelum Hindu/ Budha masuk ke Nusantara, masyarakat gunung di Nusantara mempersepsi puncak gunung adalah tempat bersemayamnya roh-roh orang mati. Rohroh tersebut berperan untuk melindungi atau menghukum masyarakatyang tinggaldigunung. Begitupun di laut, masyarakat Jawa dalam hal ini Yogyakarta selalu mengadakan upacaraupacara dimaksudkan untuk selalu mengadakan hubungandenganalamsupranatural,karenaadanya kepercayaan umumnya masyarakat Jawa masa lalu terhadap keberadaan Kanjeng RatuKidul.

Upacara-upacara keagamaan yang diabadikan Rony, dalam bahasan ini upacara Labuhan yang dilaksanakan oleh masyarakat Yogyakarta dan Kasada yang dilaksanakan oleh masyarakat Tengger merupakan bentuk mendekatkan diri dengan alam supranatural beserta roh-roh yang menjagaalamtersebut,jugamemintaperlindungan sertakesejahteraan. Namun, seiringwaktudalam kehidupan masyarakat Jawa terjadi akulturasi terhadapagamabaru, yaituHindu-Budha.Ketika orang Nusantara memeluk agama Hindu/Budha persepsi tentang gunung bergeser. Puncak gunung tidak lagi menjadi (hanya) tempat tinggal para

\begin{tabular}{l}
\hline Ecosystem Publishing, 2017), h. 60 \\
17 https://indonesiana.tempo.co/read/71612/2016/04/23/ \\
hando kowidagdo/merapi-dan-orang-jawa (Diakses pada
\end{tabular} Juni 2018) 
roh, tetapi (juga) menjadi tempat tinggal para dewa.KepercayaanIndiainiterbawakeNusantara bersamadenganmasuknyaagamaHindu/Budha.

Akulturasi berlanjut dengan masuknya Islam di Indonesia. Di era Islam dan zaman modern, persepsi manusia akan Tuhan kembali bergeser. Beberapa kepercayaan tentang gunung diwarnai oleh agama Islam. Persepsi masyarakat gunung juga mulai diwarnai oleh pengetahuan modern bersama dengan masuknya ilmu pengetahuan tentang gunung.

Seperti kebudayaan Indonesia asli dan Hindu, kebudayaan Islamitupunberpusatkepadatenaga yang gaib (Tuhan), yang dalam kebudayaan (agama) IslamdinamakanAllah. ${ }^{18}$ Namunberbedadengan animism dan dinamisme, dalam kepercayaan Islam terdapat suatu jarak antara manusia, Allah, dan alam.

Dalamayat-ayat Al-Quran, kitabsuciagama Islam, disimpulkan tentang perhubungan Allah, manusia, dan alam.Allah yang maha kuasa itu adalah asal pencipta segala sesuatu.DiciptakanNya alam semesta dan diatur-Nya matahari dan bintang-bintang, diatur-Nya hujan membasahi tanah, disuburkan-Nya bumi dan ditumbuhkanNyatumbuh-tumbuhandiatasnya. ${ }^{19}$ Sepertiyang tertulis di dalam Al-Qur'an Surat Al-A'raf Ayat 54:

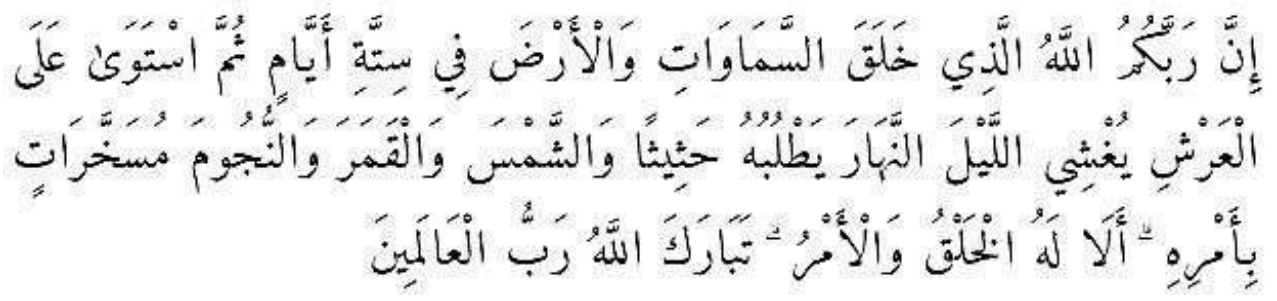

"Sesungguhnya Tuhan kamu ialah Allah yang telah menciptakan langit dan bumidalam enammasa, lalu Diabersemayam diatas 'Arsy.Diamenutupkan malam kepada siangyang mengikutinya dengan cepat, dan (diciptakan-Nya pula) matahari, bulan dan bintang-bintang (masing-masing) tunduk kepada perintah-Nya.Ingatlah, menciptakan dan memerintah hanyalah hak Allah. Maha Suci Allah, Tuhan semestaalam."

\footnotetext{
18 Jacobus Ranjabar, Sistem Sosial Budaya Indonesia

Suatu Pengantar, (Bandung: Alfabeta, 2014), h. 96

19 Jacobus Ranjabar, Sistem Sosial Budaya Indonesia Suatu Pengantar, h. 97
}

PemahamanmanusiaakanTuhandalamIslam, mengubah persepsi manusia akan Tuhan dalam ajaran sebelumnya telah di anut dalam kepercayaan animisme dan dinamisme. Namun, kepercayaan lamatersebuttidakhilangbegitusajadalamsikap maupun perilaku masyarakat gunung dan laut dalaminteraksimerekadenganlingkungannya.Hal tersebut menggambarkan adanya proses akulturasi di Indonesia.

Proses akulturasi itulah yang kemudian dijelaskan secara visual oleh Rony Zakaria dan menjadi rangkaian foto cerita berjudul "Men, Mountains and the Sea". Dalam karya foto tersebut, proses akulturasi sudah terlihat pada foto pertama, namunhanyatergambarsedikit,dariadanyacahaya lampudiantarapegunungan, menggambarkanada kebaharuan dalam kehidupan masyarakat Tengger. Berlanjut pada fotokedua, yaitu suasana upacara Labuhan di pantai Parangkusumo. Akulturasi terlihat dari adanya berbagai kepercayaan yang di anut, terlihat dari pakaian yang dikenakan oleh para peserta upacara yang datang.Ada yang memakai baju kemeja putih, ada yang memakai peci dan sarung, ada yang memakai topi caping, dan juga terlihat perempuan berkerudung. Selain itu, akulturasibudayajugaterlihatpadafotoketiga yang berhubungan dengan foto keempat. Pada

foto ketiga, terdapat seorang pria Tengger mengendarai kuda di antara pegunungan, meng gambarkan hidup masyarakat Jawa yang tradisional, namun pada foto keempat terdapat benang merah di mana seorang pria mengenakan topi fedora bertuliskan "world cup", menunjukkan bahwa ada proses modernisasi di sana. Begitupun dengan 
orangyangberdoadanbersandardipagartembok yangadapadafototersebut,menggambarkanbahwa walaupun terbuka dengan modernisasi, tetapi mereka tetap berpegang teguh pada adat istiadat.

Demikianlah proses akulturasi yang coba dikonstruksi oleh Rony Zakaria ke dalam visual. Proses akulturasi yang terjadi merupakan usaha pencarian akan Tuhan. Beragam bentuk hewan, tumbuh-tumbuhan, atau benda-benda mati seperti batu dan gunung menjadi sarana pencariannya menuju Tuhan.Apapun upaya tersebut adalah ikhtiar manusia memahami kekuasaan di luar dirinya terkait sesuatu yang harus disembah, dan berlindung atas-Nya.Kesemuanya adalah indikasi bahwa manusia selalu mencari hakikat Tuhan dan agama. ${ }^{20}$

Menariknya, catan penting penulis adalah kepercayaan lama tersebut tidak hilang begitu saja dalamsikapdanperilakumasyarakatgunungdan lautdalaminteraksimerekadenganlingkungannya yangsemakinmodern.Tampakjelasdalamkonteks objek riset ini, Masyarakat Jawa masih percaya bahwakekuatansupranaturalyangtidakbisadilihat dengan mata ada di mana-mana, dan kekuatan tersebut terhubung dengan media, dalam hal ini adalah gunung dan laut yang menjadi medianya. Karenaitulahmerekamemaknaigunungdanlaut sebagai media untuk dekat denganTuhan.]

\section{E. KESIMPULAN}

Pertama, Gunung dan Laut sebagai Media untuk Dekat dengan Tuhan. Praktik keagamaan ataupunupacarayangdilakukanmerupakanbentuk negoisasi manusia terhadap alam supranatural. Mereka menganggap jika mampu bernegoisasi kekuatanlainitu, hidupnyaakanterbantuolehalam semesta. Sebaliknya, jika tak mampu menegoisasi dengan alam semesta, akan celaka pula. Negosiasi tersebut diwujudkan dengan adanya upacara, yakniLabuhan,dimanalautmenjadimediauntuk

\footnotetext{
${ }^{20}$ Rusmin Tumanggor dan Kholis Ridho, Antropologi Agama, (Ciputat: UIN Press, 2015), hal. 36
}

dekat dengan Tuhan. Sedangkan Upacara Kasada, menjadikan gunung sebagai media untuk dekat dengan Tuhan.

Kedua, Agama Lokal Terus Beradaptasi dengan Budaya Baru, Termasuk Agama dan Modernitas. Masyarakat Jawa dahulu kala telah mengenal Tuhan. Pengenalan Tuhan dilakukan pertama-tama dengan pemujaan roh dan bendabenda,yaituanimismedandinamisme.Setelahitu, masuklah Hindu-Budha dan berkembang di Pulau Jawa.Darisanalahterjadiperpaduanagamalokal denganagamabaru.Diantarapengaruhyangpaling jelasdarikebudayaanHindu-Budhaterhadaporang Jawa dapat dilihat dari kepercayaan orang Jawa, yang hormat terhadap kekuatan benda dan roh, beralih pada dewa-dewa yang menguasai benda dan roh itu.Ketika animisme dan dinamisme percaya pada kekuatan bulan, maka Hindu kemudian kepercayaan itu ditambah dengan adanya dewa yang menjaga dan menguasai bulan.

Setelah itu, Islam masuk ke Indonesia.Islam yang dibawa orang Persia berbau mistik karena orang Persia telah lama berhubungan dengan orang-orang Gujarat-India.Dari situlah Islam berkembang, bersentuhan dengan agama Hindu. ${ }^{21}$ Maka, terjadilah akulturasi, dari kepercayaan animisme-dinamisme, Hindu-Budha, lalu Islam

\section{DAFTAR PUSTAKA}

Achmad, Sri Wintala. Filsafat Jawa, Menguak Filosofi, Ajaran, dan Laku Hidup Leluhur Jawa. Yogyakarta: Araska, 2017.

Ajidarma, Seno Gumira.Kisah Mata, Fotogafi antara Dua Subjek: Perbincangan tentang Ada. Yogyakarta: Galang Press,2002.

Batoro, Jati. Keajaiban Bromo Tengger Semeru. Malang:Universitas Brawijaya Press, 2017.

Budiman, Kris. Semiotika Visual: Konsep, Isu, dan Problem Ikonisitas. Yogyakarta: Jalasutra, 2011.

\footnotetext{
${ }^{21}$ Aristo Farela, A Short History of Java, (Surabaya: Ecosystem Publishing, 2017), h. 62
} 
Bungin, Burhan. Sosiologi Komunikasi. Jakarta: Kencana, 2006.

Darmawan, Ferry.Dunia Dalam Bingkai.

Yogyakarta: Graha Ilmu, 2009.

Carroll, Henry. Read this if You Want to Take Great Photographs. London: Laurence King Publishing Ltd, 2014.

Endraswara, Suwardi. Metodologi Penelitian Kebudayaan. Yogyakarta: Gajah Mada University Press, 2012. . Mistik Kejawen.

Yogyakarta: Narasi, 2018.

Farela,Aristo.A ShortHistoryofJava,Sejarah Singkat Tentang Pulau Jawa, Kultur, Manusia dan Budayanya. Surabaya: Ecosystem Publishing, 2017.

Fiske, John. Pengantar Ilmu Komunikasi Edisi Ketiga. Jakarta: Rajawali Pers, 2016.

Hanafie, Sri Rahaju Djatimurti Rita. Ilmu Sosial Budaya Dasar. Yogyakarta: CV. ANDI OFFSET, 2016.

Hargono, Bambang. dkk. Sabo Merapi: Antara Mitos dan Teknos. Balai Besar Wilayah Sungai Serayu Opak, 2012.

Hoed, Benny H.Semiotik \& Dinamika Sosial Budaya. Depok: Komunitas Bambu, 2014.

Ida, Rachmah. Metode Penelitian StudiMediadan Kajian Budaya Edisi Pertama. Jakarta: Kencana, 2014.

Kriyantono, Rachmat. Teknik Praktis Riset Komunikasi. Jakarta: Kencana, 2014.

Liliweri, Alo. Makna Budayadalam Komunikasi Antarbudaya. Yogyakarta: LKiS, 2002.

Morissan. TeoriKomunikasi: Individu Hingga Massa. Jakarta: Kencana, 2015.

Muhammad, Abdulkadir. Ilmu Sosial Budaya Dasar Edisi Revisi.Bandung:PT. Citra Aditya Bakti, 2011.

Prasetya, Erik.On Street Photography. Jakarta: KPG [Kepustakaan Populer Gramedia], 2014.
Ranjabar, Jacobus. Sistem Sosial Budaya Indonesia SuatuPengantar. Bandung: Alfabeta, 2014. Sadono, Sri. Serial Fotomaster Komposisi Foto. Jakarta: PT. Elex Media Komputindo, 2015. Sobur, Alex.Analisis Teks Media. Bandung: PT. Remaja Rosdakarya, 2006.

Semiotika Komunikasi. Bandung: PT. Remaja Rosdakarya,2009.

Soedjono, Soeprapto. Pot-Pourri Fotografi. Jakarta: Universitas Trisakti, 2007.

Sugiyono. Metode Penelitian Kuantitatif, Kualitatif, dan R\&D. Bandung: Alfabeta, 2013.

Sujarweni, V. Wiratna. Metodologi Penelitian. Yogyakarta: Pustaka Baru Press, 2014.

Sunardi, St. Semiotika Negativa.Yogyakarta: Penerbit Buku Baik Yogyakarta, 2004.

Tinarbuko, Sumbo.Semiotika Komunikasi Visual. Yogyakarta: Jalasutra, 2012.

Triyoga, Lucas Sasongko. Merapi dan Orang Jawa: Persepsi dan Kepercayaannya Jakarta: Grasindo, 2010.

Tumanggor, Rusmin dan Kholis Ridho. Antropologi Agama. Ciputat: UIN Press, 2015.

Tumanggor,Rusmin.dkk.IlmuSosialdanBudaya Dasar. Jakarta: Kencana, 2010.

Twikromo, Y. Argo. Ratu Kidul. Yogyakarta: Yayasan Bentang Budaya, 2000.

Wibowo, Indiawan Seto Wahyu.Semiotika Komunikasi. Jakarta: Mitra Wacana Media, 2011.

Wijaya, Taufan.Foto Jurnalistik.Jakarta: PT. Gramedia Pustaka Utama, 2014.

-Photo Story Handbook: Panduan Membuat Foto Cerita. Jakarta: PT. Gramedia Pustaka Utama, 2016.

\section{Wawancara}

Wawancara Pribadi dengan Rony Zakaria pada 22 Juni 2018. 


\section{Karya Ilmiah}

Hidayat, Mafrika Wahyu, "Analisis Semiotik Foto Pada Buku Jakarta Estetika Banal Karya Erik Prasetya”, Fakultas Ilmu Dakwah dan Ilmu Komunikasi UIN Syarif Hidayatullah Jakarta, 2014

Wicaksono, Muhammad Hendartyo Hanggi, "Makna Tradisi Budaya 'Pacoa Jara' dalam Foto (Analisis Semiotika Terhadap Foto Karya RomiPerbawaBerjudulTheRidersofDestiny padaAjangPameran TheJakartaInternational Photo Summit Tahun 2014)", Fakultas Ilmu Dakwah dan Ilmu Komunikasi UIN Syarif Hidayatullah Jakarta, 2014

Zulmi,IsyeNaisila,"MaknaBencanadalamFoto Jurnalistik (Analisis Semiotika Foto Terhadap Karya Kemal Jufri pada Pameran Aftermath : Indonesia in Midst of Catastrophes Tahun 2012)", Fakultas Ilmu Dakwah dan Ilmu KomunikasiUINSyarifHidayatullahJakarta, 2014

\section{Website}

http://destinasian.co.id/dokumentasi-gunung-lautdan-manusia/

http://et.klipingsastra.com/2015/08/gunung-

dalam-kosmologi-jawa.html

http://scdc.binus.ac.id/klifonara/2016/03/sejarah-

singkat-fotografi/

http://www.cintalaut.com/2013/07/karakteristik-

masyarakat-pesisir-dalam.html

http://www.dw.com/id/ritual-dan-tradisi-

memotret-hubungan-manusia-dengan-

alam/a-18967467

http://www.hasmi.org/larung-sesaji-pantai-lautselatan/

http://www.herrytjiang.com/sejarah-fotografi/ https://indonesiana.tempo.co/read/7161

2/2016/04/23/handokowidagdo/merapi-danorang-jawa https://issuu.com/ennyvales/docs/destinasian_ indonesia

https://mangkoko.com/ruang_baca/psikologiwarna-hitam-bukanlah-warna

https://newstoday.id/apa-itu-cincin-api-pasifik/ https://snapshot.canon-asia.com/indonesia/article/

id/gestalt-theory-in-street-photography https://snapshot.canon-asia.com/indonesia/article/ id/gestalt-theory-in-street-photography https://travel.kompas.com/read/2017/05/

14/180300327/mengapa.masyarakat.suku. tengger.suka.menggunakan.sarung https://www.hipwee.com/feature/10-fakta-tentangkawasan-cincin-api-yang-katanya-semakinaktif-orang-indonesia-wajib-tahu/ https://www.merdeka.com/peristiwa/pantai

parangkusumo-gerbang-istana-nyi-roro-kidul. html

https://www.pegipegi.com/travel/mengenalupacara-kasada-di-tengah-eloknya-gunungbromo/

https://www.ronyzakaria.com/about www.lensculture.com 